\title{
EVENTOS
}

\section{CONFERÊNCIA INTERNACIONAL SOBRE ENSAIOS ACELERADOS DE PAVIMENTOS}

18 a 20 de outubro de 1999

Reno, Estados Unidos

\section{Washington Peres Núñez Jorge Augusto Ceratti}

UFRGS - Univ. Federal do Rio Grande do Sul

\section{José Augusto de Oliveira}

DAER-RS - Departamento Autônomo de Estradas de Rodagem do Estado do Rio Grande do Sul

\section{INTRODUÇÃO}

De 18 a 20 de outubro de 1999 realizou-se na cidade de Reno (Estados Unidos) a International Conference on Accelerated Pavement Testing. O evento foi organizado sob os auspícios do Comitê para Ensaios Acelerados e em Verdadeira Grandeza do Transportation Research Board, e propiciou o intercâmbio de informações técnicas sobre ensaios acelerados de pavimentos, com ênfase na previsão de desempenho, nos materiais e na instrumentação.

Participaram da conferência 164 representantes de 23 países dos 5 continentes. No plano institucional, destacam-se as seguintes participações: ASSHTO (Estados Unidos), ARRB (Austrália), Asphalt Institute (Estados Unidos), CEDEX (Espanha), CSIR (África do Sul), 8 Departamentos de Transportes dos Estados Unidos, FAA (Estados Unidos), FHWA (Estados Unidos), LCPC (França), University of California, Berkeley e US Army Corps of Engineers (Estados Unidos).

A programação técnica consistiu de sessões plenárias e de sessões simultâneas. Dos 64 trabalhos apresentados, 38 provinham dos 
Estados Unidos, 12 da Europa (8 países), 5 da Oceania (Austrália e Nova Zelândia), 5 da África do Sul, 3 da Ásia (Japão e China) e 1 da América Latina (Brasil).

Os principais assuntos abordados nos 47 artigos das sessões simultâneas foram: previsão de desempenho (10 artigos), materiais de base e subleito (7), instalações para ensaios em verdadeira grandeza (7), ensaios em escala reduzida (6), instrumentação (4), interação veículo-pavimento (3), pavimentos de concreto (3), whitettoping (3).

O Brasil esteve representado pelos professores Jorge Augusto Ceratti e Washington Peres Núñez da UFRGS e pelo engenheiro José Augusto de Oliveira do DAER/RS, que relataram resultados da pesquisa sobre emprego de basaltos alterados em pavimentos de baixo volume de tráfego, desenvolvida na Área de Pesquisas e Testes de Pavimentos em Porto Alegre.

\section{PROGRAMAS DE LONGO PRAZO RELATADOS NAS SESSÕES PLENÁRIAS}

Os 17 artigos apresentados nas sessões plenárias focalizaram 14 programas de longo prazo de ensaios acelerados de pavimentos, caracterizados pelo papel influente que tiveram e têm. Os escopos dos programas variam, mas há razões semelhantes para o sucesso que alcançaram:

- O ensaios acelerados de pavimentos são parte de um esforço de múltiplas facetas, que inclui extenso trabalho laboratorial.

- A abordagem cooperativa resulta em implementação rápida e ampla dos resultados.

\subsection{Síntese de Alguns Artigos Apresentados nas Sessões Plenárias}

$\mathrm{O}$ artigo apresentado por Kekwick et al. focalizou os fatores que contribuíram para o notável sucesso do programa de ensaios acelerados de pavimentos com emprego do South African Heavy Vehicle Simulator (HVS), que vem se desenvolvendo há quase 30 anos. 
Entre os desenvolvimentos específicos que se tornaram possíveis graças aos ensaios acelerados de pavimentos foram destacados:

- o método empírico-mecanístico de dimensionamento de pavimentos da África do Sul;

- a quantificação do expoente dos fatores de equivalência de carga (diferente da tradicional potência 4);

- o emprego do DCP (cone sul-africano);

- sofisticados equipamentos para acompanhamento da condição do pavimento (multi depth deflectometer, crack activity measurement, road surface deflectometer, etc.);

- a quantificação das tensões de contato pneu/pavimento.

O artigo alertou para a necessidade de:

- uma abordagem coerente, que inclua estratégias a curto e longo prazo, empregando técnicas de gerência de tecnologia;

- cooperação intensa entre as autoridades rodoviárias e pesquisadores para definir necessidades e produtos;

- um esforço concentrado para assegurar a transferência e implementação de tecnologia.

Gramsammer et al. apresentaram uma retrospectiva dos ensaios acelerados de pavimentos desenvolvidos com emprego do Manège de Fatigue (simulador radial de tráfego) do LCPC, em Nantes, França. Desde 1984 mais de 50 milhões de ciclos de carga foram aplicados a mais de 180 seções experimentais.

Um experimento de destacada importância foi a validação do desempenho de uma estrutura de pavimento semi-rígido invertido. A estrutura invertida foi adotada imediatamente pela SCETAROUTE proporcionando uma economia de US\$100.000 por $\mathrm{km}$, em relação à estrutura convencionalmente empregada.

Sharp et al. forneceram uma visão do bem-sucedido programa australiano ALF (Accelerated Loading Facility - Simulador de Tráfego Linear, similar ao existente no Rio Grande do Sul). A base do programa é ensaiar pavimentos em escala real sob tráfego convencional e relacionar os resultados com o desempenho sob 
tráfego acelerado. Ademais, os experimentos são complementados com ensaios de laboratório.

Mais de 200 experimentos foram desenvolvidos em 120 pavimentos experimentais, aos quais foram aplicados 24.200 .000 ciclos de carga com o ALF ou cerca de 2,7 × $10^{8}$ cargas de eixo simples equivalente.

Os quatro assuntos principais abordados foram:

- ensaios de pavimentos em serviço;

- procedimento de dimensionamento e construtivos;

- materiais e práticas alternativas;

- estratégias de gerência.

Newcomb et al. relataram o experimento $M n R O A D$, iniciado em 1994. Com um custo de 25 milhões de dólares, apresenta 40 seções experimentais, sendo 17 de baixo volume de tráfego. Um aspecto impressionante do $M n R O A D$ é a extensiva instrumentação empregada.

Entre os objetivos do projeto destacam-se:

- a verificação dos modelos empíricos para dimensionamento;

- o desenvolvimento de modelos mecanísticos;

- o desenvolvimento de funções de equivalência de carga;

- o estudo da influência de novas configurações de veículos;

- o estudo da variabilidade dos parâmetros de pavimentos.

Epps et al. salientaram os principais detalhes do projeto WesTrack construído nas proximidades de Reno, em 1996, com um custo de 14,5 milhões de dólares. A pista oval tem $3 \mathrm{~km}$ de extensão, inclui 26 seções, sendo trafegada por caminhões controlados à distância (sem motoristas). Os objetivos principais do projeto são o desenvolvimento de especificações baseadas no desempenho para misturas asfálticas e a verificação em campo da metodologia Superpave para projeto de misturas asfálticas.

A programação da conferência incluiu uma visita ao projeto WesTrack na tarde do dia 19 . Os resultados do experimento resultaram em avanços no controle da qualidade de construção de pavimentos, em 
especificações para materiais e técnicas de recuperação de pavimentos.

\section{A SESSÃO SIMULTÂNEA SOBRE PREVISÃO DE DESEMPENHO}

A sessão sobre previsão de desempenho tinha como um dos objetivos exemplificar:

- como desenvolver modelos;

- como os modelos podem ser criados a partir de estudos de desempenho de pavimentos a longo prazo ou a partir de ensaios acelerados de pavimentos;

- a verificação de tais modelos.

No global os artigos apresentados nesta sessão foram interessantes, mas deixaram lacunas. Salienta-se a necessidade de:

observar cuidadosamente e comparar os comportamentos de seções submetidas a tráfego acelerado com pavimentos em serviço. Que tipo de dano é observado e quais as causas potenciais? Os pavimentos reais se comportam da mesma maneira que os submetidos a cargas aceleradas? Se não, como transferir os resultados de ensaios acelerados para situações reais?

caracterizar cuidadosamente os materiais.

modelar cuidadosamente a carga aplicada. Visto a acentuada degradação superficial observada em vários experimentos submetidos a cargas aceleradas, modelar corretamente as tensões de contato é fundamental.

modelar cuidadosamente a resposta do pavimento. Os modelos elático-lineares podem ser insuficientes para modelar $o$ comportamento de pavimentos submetidos a cargas aceleradas, devido aos longos períodos de solicitação, curtos intervalos de repouso (pelo qual o acúmulo de tensões residuais e deformações permanentes podem ser mais sérios em pavimentos com simulações aceleradas) e os elevados níveis de tensão. 


\section{CONCLUSÕES GERAIS DA CONFERÊNCIA}

A 1999 International Conference on Accelerated Pavement Testing foi um excelente encontro que estabeleceu o ponto de partida para a cooperação internacional, na procura de maior eficiência no uso e aplicação dos ensaios acelerados de pavimentos.

Dos trabalhos expostos e debates gerados listam-se sucintamente alguns aspectos de destaque:

- Os ensaios acelerados de pavimentos têm sido empregados com sucesso na avaliação de solos e materiais granulares, de novos materiais e de estruturas alternativas de pavimentos, mas esse sucesso precisa ser mais divulgado (marketing);

- O estágio atual de compreensão das cargas dinâmicas e das verdadeiras tensões de contato pneu-pavimento é satisfatório e estes parâmetros podem ser incluídos no dimensionamento;

- O número de modelos desenvolvidos para prever deformação permanente de camadas asfálticas e granulares aumenta rapidamente. Espera-se que isto tenha um impacto favorável na evolução do dimensionamento mecanístico;

- Os ensaios acelerados de pavimentos têm mostrado em muitas ocasiões que o expoente para cálculo dos fatores de equivalência de carga é freqüentemente maior do que 4;

- Os ensaios acelerados de pavimentos devem auxiliar no desenvolvimento de novos modelos de desempenho. Os ensaios sob condições controladas propiciam esse desenvolvimento;

- O efeito da água nos diferentes mecanismos de ruína dos pavimentos precisa ser quantificado;

- Deve-se entender que os ensaios acelerados de pavimentos são um instrumento fundamental para a gerência de pavimentos e que portanto exigem cuidadoso planejamento estratégico;

- Os ensaios acelerados de pavimentos são caros, o que estimula fortemente a cooperação internacional. Compartilhar informações é imperativo também para evitar a repetição de erros. 